\title{
Lying down with protective setae as an alternative antipredator defence in a non-webbing spider mite
}

\author{
Shuichi Yano* and Kanako Shirotsuka
}

\begin{abstract}
An antipredator defence in the citrus red mite Panonychus citri, which does not produce protective webs, was examined experimentally. P. citri adult females lie down on citrus leaf surfaces with their dorsal setae (hair) directed in all upper directions. They seldom move in response to physical stimuli. Compared to normal lying females, both manipulated non-lying females and hair-removed females suffered higher predation by predatory mites. A predator approaching the body surface of a lying female inevitably created elasticity with a confronting seta, which eventually repelled the predator away from the female. These observations indicated that lying down with protective setae functions as an antipredator defence in $P$. citri females. This inflexible defence could also explain why the mite rarely runs away, even when it is consumed together with host plant leaves (via coincidental intraguild predation) by gigantic swallowtail caterpillars, against which protective setae are totally ineffective.
\end{abstract}

Keywords: Citrus red mite; Dorsal setae; Lying down; Predatory mite; Antipredator defence

\section{Introduction}

The life-dinner principle (Dawkins and Krebs 1979) predicts that antipredator behaviour should evolve faster than prey capture behaviour because successful defence means life to the prey, but only a lost meal to the predator. Spider mite and predatory mite systems offer one of the best examples of such predator-prey interactions: many spider mite species have developed co-operative defences against predators using three-dimensional protective webs (Saito 1986a; 1986b; Mori et al. 1999; Yano 2012), although the webs are ineffective against some predatory mites that specialize in preying on web-spinning spider mites (McMurtry et al. 1970; Sabelis and Bakker 1992; Shimoda et al. 2009). However, spider mites such as the citrus red mite [Panonychus citri (McGregor)] that do not produce protective webs (Saito 1983) also thrive under the same ecological conditions as mites producing protective webs. Since the twodimensional webs produced by $P$. citri on leaf surfaces do not cover the body of the mite (Saito 1983), the webs obviously do not defend the mite from predators. Moreover, P. citri frequently moves between plant leaves (Wanibuchi

\footnotetext{
* Correspondence: yano@kais.kyoto-u.ac.jp

Laboratory of Ecological Information, Graduate School of Agriculture, Kyoto University, Sakyo-ku, Kyoto 606-8502, Japan
}

and Saito 1983), indicating that the mite does not concentrate webs in a certain place on a plant. Therefore, we hypothesised that $P$. citri should have an alternative antipredator defence to producing protective webs.

Another unsolved mystery of P. citri is an apparently maladaptive trait: the mite rarely runs away even when it is dying because of coincidental intraguild predation from swallowtail caterpillars that consume mites together with citrus leaves (Shirotsuka and Yano 2012). In stable environments, traits that have a considerable negative impact on fitness are expected to be ultimately eliminated by natural selection. However, such traits can be maintained if they are advantageous in other circumstances (Nedelcu et al. 2011). Therefore, we hypothesised that by not moving in response to external stimuli, mites should realise a considerable benefit that overwhelms the cost of intraguild predation.

The mite has a striking appearance (Figure 1b, above) for people other than acarologists: extremely long dorsal setae compared to the body size, a massive knot at the bottom of each seta, a perfect lying posture on a leaf surface and a vivid body colour like alpine flowers. In particular, the function of dorsal setae in mites has been poorly explored; they are only used as taxonomic characters. In

\section{穴}




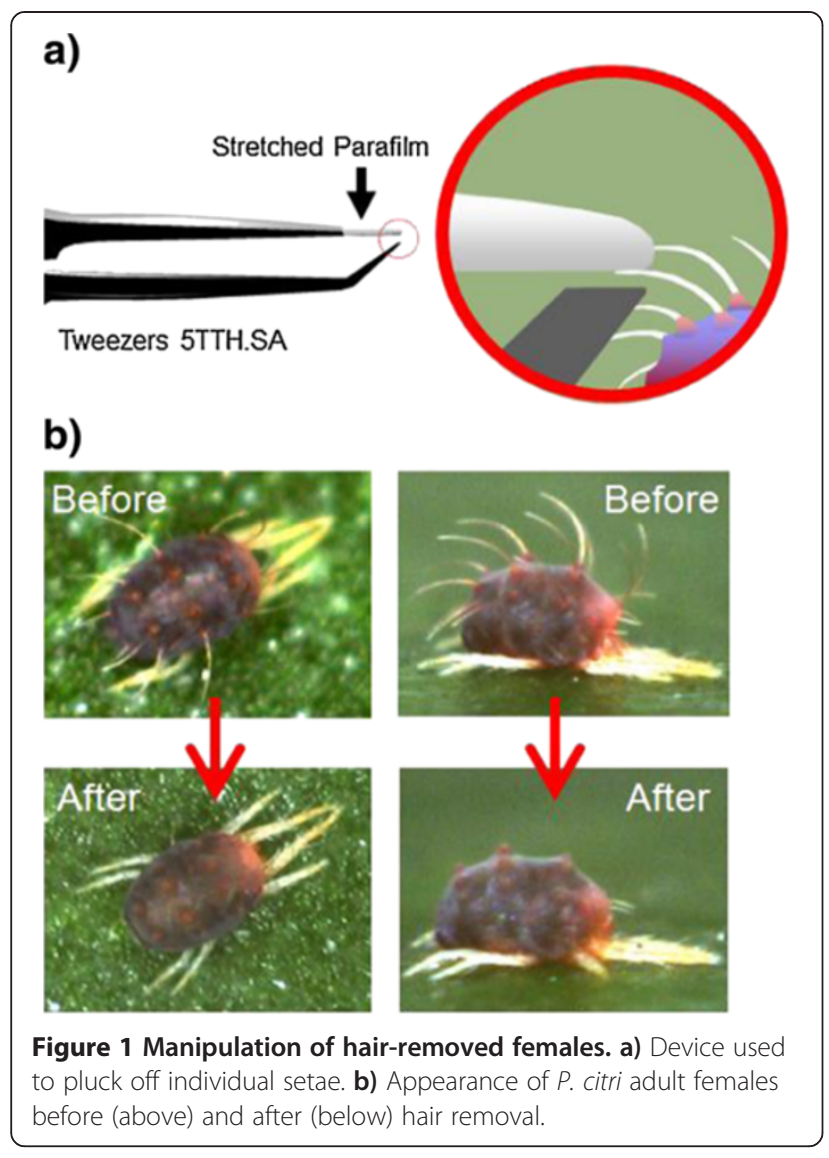

this study, we experimentally removed dorsal setae from $P$. citri and directly demonstrated the defensive function of mite setae against predatory mites for the first time. We also determined the relationship between these traits and the antipredator strategy of the mite.

\section{Materials and methods \\ Mites}

The study population of $P$. citri was collected from a deciduous citrus shrub Poncirus trifoliata L. (Raf.) and separately maintained on leaf discs of kidney bean (Phaseolus vulgaris L.; bean population) or grapefruit (Citrus paradise Macf.; citrus population) that were pressed onto watersaturated cotton in Petri dishes $(90 \mathrm{~mm}$ diameter, $14 \mathrm{~mm}$ depth). Although P. citri use citrus host plants in the wild, the mite is easily reared on bean leaf discs in the laboratory (Fukaya et al. 2013). The dishes were placed in transparent plastic containers and kept at $25 \pm 2^{\circ} \mathrm{C}$ and $50 \pm 5 \%$ relative humidity, with a photoperiod of 16-h L:8-h D (hereafter described as "laboratory conditions"). We maintained the population on each plant disc for more than three generations before conducting the following experiments.

For comparison, we also used a polyphagous spider mite Tetranychus kanzawai Kishida, which constructs complicated three-dimensional webs over leaf surfaces (Saito 1983).
The study population of T. kanzawai was collected from a strawberry garden and maintained on bean leaf discs in the same manner described above.

The predatory mites Euseius sojaensis (Ehara) and Neoseiulus womersleyi Schicha are potential predators of P. citri (e.g. Osakabe et al. 1986; Inoue et al. 1987; Katayama et al. 2006). The former species is a typical generalist predator which feeds on both plant materials and spider mites, while the latter species mainly feeds on tetranychid mites (McMurtry and Croft 1997; Nguyen and Shih 2012). The study population of E. sojaensis was collected from kudzu vines Pueraria lobata (Willd.) Ohwi and was reared on tea pollen on bean leaf discs. The study population of $N$. womersleyi was collected from a hydrangea bush and reared on bean leaf discs that were heavily infested with Tetranychus urticae Koch as prey (30-50 female adults and individuals of other stages per leaf). The discs were maintained under laboratory conditions.

Adult female spider and predatory mites used in the following experiments were similar in size $(\leq 0.5 \mathrm{~mm})$. Detailed observations and transfers using a fine brush were only possible under a stereomicroscope. All tests described below were carried out between 1300 and $1700 \mathrm{~h}$.

\section{Frequency of lying down females}

To compare the frequency of lying down $P$. citri with that of T. kanzawai that produce protective webs, we observed the behavioural status (lying or otherwise) of the two species on bean leaf discs under laboratory conditions. We used bean leaves in order to equalize the structure of leaf surfaces on which the mites were observed. We introduced 10 newly emerged female adults of $P$. citri (bean population) onto each of seven bean leaf discs and T. kanzawai onto each of eight discs using a fine brush. The size of leaf discs was ca. $25 \mathrm{~cm}^{2}$. After $24 \mathrm{~h}$ of acclimation, we documented the behavioural status of the females, i.e. whether they were lying or acting otherwise (moving). Since we never observed P. citri females feeding while moving, they seemed to feed while lying down. We observed each female only once. The number of valid observations was 62 and 78 for P. citri and T. kanzawai, respectively. The proportions of lying females were compared using Fisher's exact probability test.

\section{Response of lying females against a physical stimulus}

To compare the behavioural response of $P$. citri females against a physical stimulus with that of $T$. kanzawai females, we physically stimulated the dorsal setae of females that were lying on bean leaf discs after the above experiment. Since the major dorsal setae of Panonychus spider mites line in four rows (Ehara and Gotoh 1992), the dorsal positions of $P$. citri, including each row and 
corresponding position in $T$. kanzawai, were defined as positions 1-4 from the front (see Figure 2). Using the tip of a fine insect pin as a neutral substance, we stimulated the respective positions of lying $P$. citri and stationary $T$. kanzawai females and documented whether the females ran away or stayed motionless. In case when a target female had disturbed an adjacent untouched female, the latter female was excluded from the experiment. The number of valid observations for each combination of positions and mite species was $>20$. The proportions of females that ran away were compared using Fisher's exact probability test.

\section{Function of lying down against predation}

To examine the defensive function of the lying posture in $P$. citri females, comparing the predation rates between lying and non-lying females was necessary. However, preparing non-lying females against predators was impossible since untouched females usually lie down and rarely move in response to a stimulus (see Results and Additional file 1). Therefore, we created artificial non-lying females as follows. We used 2- to 4-day-old P. citri female adults from the citrus population. First, we fixed the female upside-down by gluing its dorsal setae with a droplet of glue (woodworking bond glue; Konishi Bond Adhesive Co., Tokyo, Japan) onto the surface of a $15 \times 15-\mathrm{mm}$ grapefruit leaf square that was pressed onto watersaturated cotton (upside-down females, $n=23$ ). Second, we introduced a female that had been subjected to a sublethal intensity of ultraviolet irradiation $(253.7 \mathrm{~nm}$ wavelength, $0.45 \mathrm{~W} \mathrm{~m}^{-2}$ for $1.5 \mathrm{~h}$ ) using a GL-6 sterilisation lamp (6 W; Ultra-Violet Box; Sogo Rikagaku Glass Works Co., Kyoto, Japan) onto the leaf square (UV irradiated females, $n=23$ ). Although the UV-irradiated females were

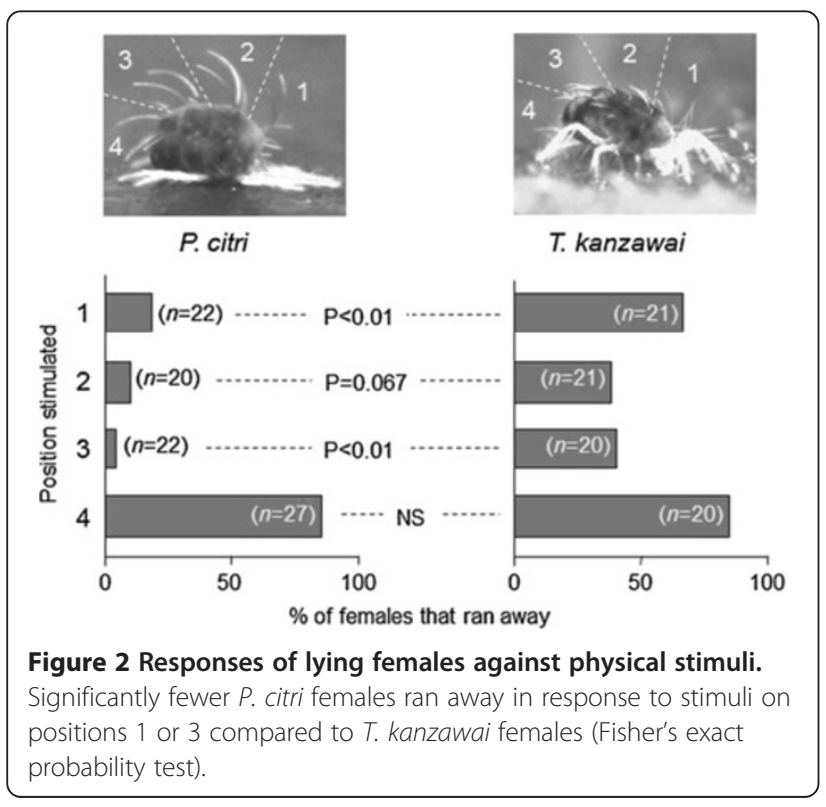

still alive, they could not lie down like normal individuals. As a control, we introduced an untouched female onto the leaf square (control females, $n=24$ ). We did not glue females in the normal lying posture as controls because it resulted in immediate death and depression of the female. Then, we introduced a 3- to 5-day-old starved female of either E. sojaensis or N. womersleyi that had been previously isolated for $48 \mathrm{~h}$ in a $1.5-\mathrm{ml}$ microtube (Treff AG, Degersheim, Switzerland) with a water droplet. This was to promote immediate predation and to make it easier to judge predation because the transparent body of a starved predator turns a vivid vermillion after it consumes prey. After $24 \mathrm{~h}$, we documented the proportion of consumed prey. The proportions were compared using Fisher's exact probability test with Bonferroni step-down correction.

\section{Function of dorsal setae against predation}

The best way to directly demonstrate the function of dorsal setae is to see what happens in their absence. However, cutting the dorsal setae off $P$. citri females without injuring them was practically impossible because of their small body size $(\leq 0.5 \mathrm{~mm})$. Instead, we plucked them off using the finest tweezers (5TTH.SA; Ideal-TeK SA, Balerna, Switzerland) as follows. We coated one tip of the tweezers with a fully stretched piece of Parafilm M (American National Can Co., Chicago, IL, USA). Then we plucked the setae off 2-day-old $P$. citri females because it was only possible to pluck setae on the second day after maturation (Yano personal observation). As we pinched individual seta using the tweezers under a stereomicroscope, the sticky coated tip trapped the target seta (Figure 1a). Hair removal from $P$. citri was possible due to the following factors. First, since $P$. citri females rarely run away in response to external stimuli, we could manipulate them while alive on leaf surfaces. Second, since each seta extends in an independent direction, we could pinch and remove them one by one, which was necessary because a seta could only be plucked along its direction. Finally, we found that the plucking of setae was only possible on the second day after female maturation. In addition, since seta removal required elaborate work under a powerful stereomicroscope, one must be careful to provide enough illumination to avoid weakening one's eyesight (S. Yano personal experience).

We confirmed that all hair-removed 2-day-old females ( $n=11)$ survived the following $24 \mathrm{~h}$ by maintaining them on $15 \times 15-\mathrm{mm}$ grapefruit leaf squares; the females lay down on the leaves as did untouched (hairy) individuals. We also confirmed that the number ( \pm SE) of eggs oviposited in $24 \mathrm{~h}$ by hair-removed females $(3.82 \pm 0.48, n=11)$ and untouched females $(3.58 \pm 0.29, n=12)$ were equivalent $(P=0.80$, Mann-Whitney $U$-test), suggesting that the both females had similarly fed and oviposited on the leaves. We confined hair-removed $(n=14)$ or hairy (control, $n=15$ ) 2-day-old P. citri females on leaf squares. Then we 
introduced a starved E. sojaensis female onto each leaf square in the manner that was described above. After $24 \mathrm{~h}$, we documented the proportion of consumed prey. The proportions were compared using Fisher's exact probability test. After the experiment was concluded, we video-recorded a starved E. sojaensis attacking a hairy $P$. citri female on a leaf square to document the moment of an unsuccessful attack.

\section{The preferences of $P$. citri and predatory mites for upper} and lower leaf sides

To compare the leaf-side preferences of $P$. citri with those of E. sojaensis and $N$. womersleyi, a detached grapefruit leaf was inserted into a 2-ml tube bottle filled with water, and the bottle was fixed so that the leaf sides were held horizontally. Water could not leak from the tube because of a small bottle neck. Then we introduced a female of $P$. citri or predatory mites onto the upper leaf-side and kept the setup under laboratory conditions. After $1 \mathrm{~h}$, we recorded the leaf side on which the female had settled. The proportions of mites settled on upper and lower sides were compared using Fisher's exact probability test with Bonferroni step-down correction.

\section{Results}

\section{Frequency of lying down females}

The observed frequency of the lying posture was significantly higher in P. citri (93.5\%) than T. kanzawai (56.4\%), suggesting that $P$. citri allocated much more time to lying compared to T. kanzawai (Figure 3).

\section{Response of lying females against a physical stimulus}

Significantly fewer $P$. citri females ran away in response to a physical stimulus on positions 1 or 3 compared to
T. kanzawai females (Fisher's exact probability test; Figure 2). The difference was nearly significant for position 2 (Figure 2). For these positions, P. citri females did not seem to move in response to physical stimuli as a rule. However, both $P$. citri and T. kanzawai females quickly ran forward in response to a stimulus on position 4 (Figure 2). Moreover, one can clearly see that setae forms and lying postures were different between the species: long setae of $P$. citri extend in independent directions, whereas short setae of T. kanzawai point in the same direction, and gaps between the mite body and the leaf surface were minimal in P. citri but variable in T. kanazawai (Figure 2).

\section{Function of lying down against predation}

Predatory mites could easily access both upside-down and UV-irradiated females from the females' exposed underside where dorsal setae were absent. Significantly more $P$. citri females that were fixed upside-down were consumed compared to normal ones that could lay down $(P=0.0084$ for E. sojaensis and $P<0.001$ for $N$. womersleyi, Fisher's exact probability test with Bonferroni step-down correction; Figure 4). Similarly, significantly more UV-C-irradiated $P$. citri females were consumed than normal ones $(P<0.001$ for both predatory mites; Figure 4$)$. The higher predation rates on $P$. citri females that could not lie indicate that lying down prevented predation.

\section{Function of dorsal setae against predation}

Although both hair-removed and hairy (normal) P. citri females lay down, significantly more hair-removed females were killed than hairy ones in the presence of a predator $(P<0.0001$, Fisher's exact probability test; Figure 5$)$, indicating that dorsal setae prevented predation.

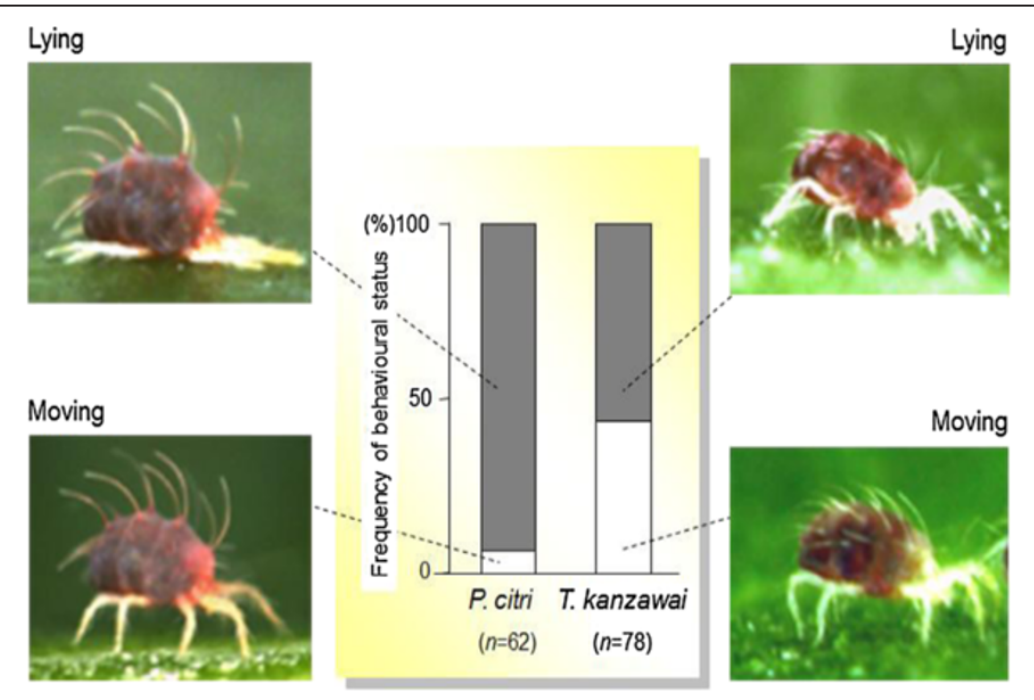

Figure 3 Frequency of lying down females in P. citri and $T$. kanzawai. The frequency of behavioural status differed significantly between the species ( $P<0.0001$, Fisher's exact probability test). 

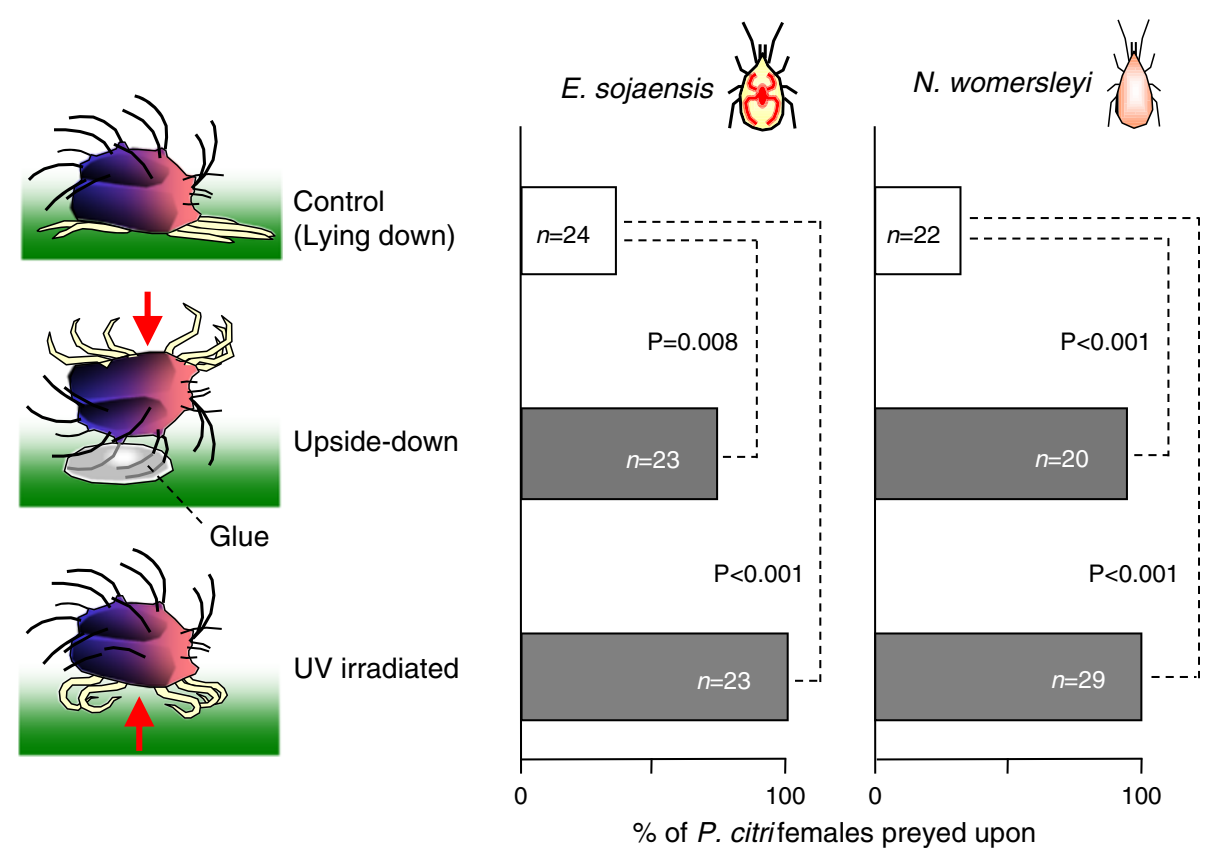

Figure 4 Function of lying down against predation. Significantly more $P$. citri females that could not lie down were consumed than normal ones (Fisher's exact probability test with Bonferroni step-down correction). Arrows indicate directions from which predators could access disabled females.

The video recordings suggested that the setae of $P$. citri females prevent the approach of and attacks by E. sojaensis females (Additional file 1). A female E. sojaensis attempting to approach the body surface of a lying female was sometimes repelled by an elastic seta (Additional file 2).

The preferences of $P$. citri and predatory mites for upper and lower leaf sides

More than half of the P. citri females (65\%) that were introduced onto the upper leaf-side remained on the side. In contrast, only one of 22 E. sojaensis females (4.5\%) and two of $25 \mathrm{~N}$. womersleyi females (8.0\%) that were

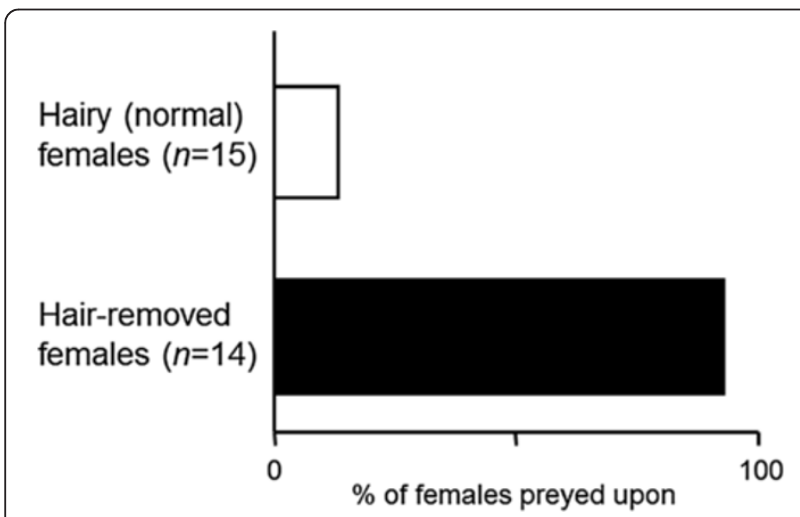

Figure 5 Function of dorsal setae against predation. Significantly more hair-removed females were killed than normal (hairy) ones in the presence of a predator $(P<0.0001$, Fisher's exact probability test). introduced onto the upper leaf-side remained on the side $(P<0.001$, Fisher's exact probability test with Bonferroni step-down correction, Figure 6), suggesting that predatory mites did not settle on an upper leaf-side as a rule.

\section{Discussion}

The high frequency with which $P$. citri females lay on leaves suggested that this trait is a constitutive one. Lying $P$. citri females did not move in response to external physical stimuli as a rule, except when they were stimulated at the tail end (position 4). These P. citri females, and most $T$. kanzawai, females did run away against stimuli, suggesting that $P$. citri females that did not move in response to a stimulus should have a selective advantage.

From this viewpoint, we examined the defensive function of the lying posture of $P$. citri females by manipulating non-lying females. The higher consumption rate of nonlying females by the both predatory mites in turn suggested that the lying posture of $P$. citri females is effective against wide range of predatory mites. We also examined the defensive function of the dorsal setae of $P$. citri females by manipulating hair-removed females. Since hair-removed P. citri females readily survived in the absence of predators, the higher predation rate for hair-removed females demonstrated that dorsal setae functioned to prevent predation.

To consume prey spider mites, the mouthpart of the predatory mite should reach the prey body surface. 


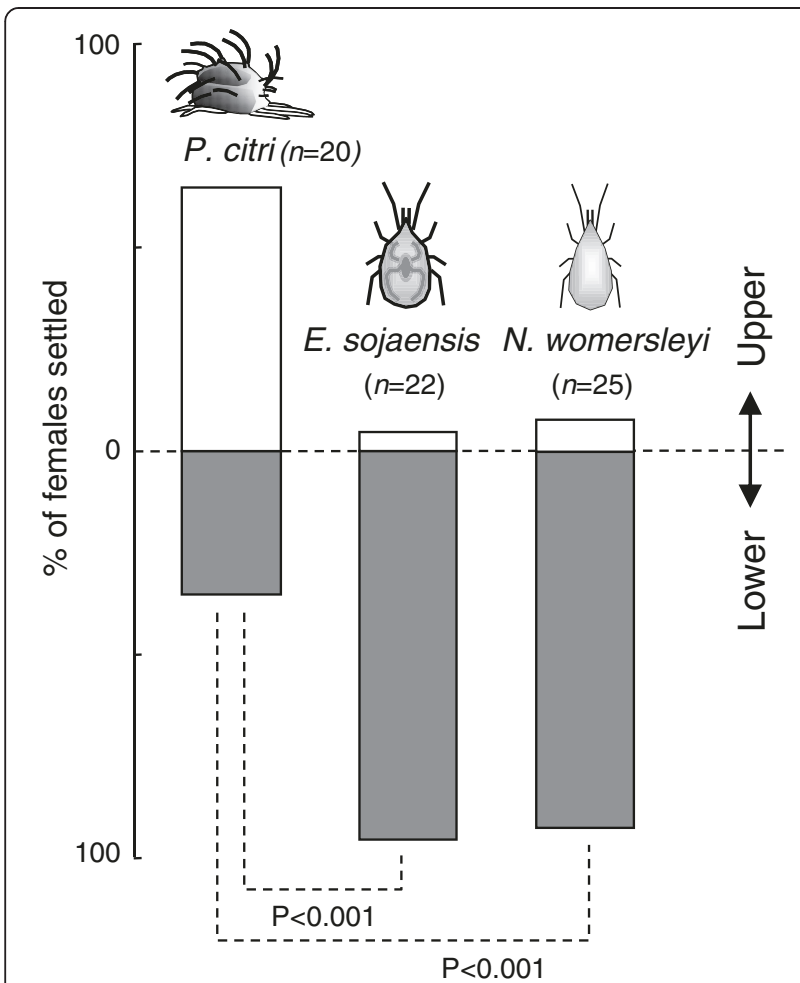

Figure 6 Leaf-side preferences of $P$. citri and predatory mites. Significantly more $P$. citri females settled on upper leaf-sides compared to predatory mite females $(P<0.001$, Fisher's exact probability test with Bonferroni step-down correction).

However, massive knots at the bottom of each seta seemed to maintain the direction of the seta, which prevented predators from approaching the prey body surface. Since the setae of lying $P$. citri extend in all upper directions, regardless of the direction of attack, predators cannot avoid confronting a seta. As a result, predator's efforts to approach the prey body surface inevitably create strong elasticity with the confronting seta, and the predator is physically repelled due to its own action (Additional file 2).

Since $P$. citri uses both the upper and lower leaf sides (Jones and Parrela 1984), the importance of repelling predators may depend on which leaf side the mite inhabits. The antipredator strategy will be highly effective on a lower leaf-side where the probability that a repelled predatory mite would come back to attack the same P. citri individual is negligible. In contrast, a predator that is repelled away on an upper leaf-side is more likely to remain on the side and may return to the same $P$. citri individual. However, we confirmed that the both predatory mites did not inhabit the upper leaf-side as a rule. Indeed, Sudo and Osakabe (2011) reported that $98 \%$ of predatory mites in the wild are found on a lower leaf-side. These results suggest that upper leaf-sides function as enemy-free spaces for $P$. citri, where its antipredator defence by lying down would be less effective. Fukaya et al. (2013) suggested that the cost to P. citri of being exposed to UV irradiation on the upper leaf-side is lower than for other spider mite species owing to the typical vivid pigmentation of this mite.

Thus, traits that compose the apparently striking appearance of $P$. citri seem highly functional from the viewpoint of antipredator defence. We hypothesise that lying down with protective setae represents an alternative antipredator defence for spider mites to producing protective webs. That is, P. citri does not have to produce protective webs that are costly in terms of reduced fecundity (Oku et al. 2009), and mites that produce protective webs do not have to lie down most of the time or possess long setae that might be a hindrance when living under a protective web.

P. citri disperses using air currents (Fleschner et al. 1956). However, its long dorsal setae are seemingly not essential for aerial dispersal because spider mites with short dorsal setae, such as Tetranychus urticae Koch and T. kanzawai, also disperse aerially (Smitley and Kennedy 1985; Osakabe et al. 2008). Although adult $P$. citri females with long dorsal setae appeared to be well defended against predatory mites, juvenile $P$. citri with shorter setae may have less protection against predators. How juvenile mites are defended against predators remains to be examined in future studies.

Since predatory mites sometimes attack $P$. citri from above (Additional file 2), P. citri has to defend in all directions except from below, where it is defended by the leaf surface. This must explain why the dorsal setae of $P$. citri are arranged and extend in all upward directions.

Although the constitutive antipredator defence of $P$. citri by lying down with protective setae is effective against predatory mites, it is totally ineffective against gigantic intraguild predators: lying $P$. citri individuals are often consumed together with leaves by swallowtail caterpillars (Shirotsuka and Yano 2012). Although P. citri and swallowtail caterpillars overlap on citrus host plants in time and space, the caterpillars are seemingly less harmful to $P$. citri than are predatory mites because the caterpillars forage randomly with respect to the presence of $P$. citri (Shirotsuka and Yano 2012), while predatory mites actively search for prey mites using various prey derived cues (e.g. Vet and Dicke 1992; Pratt and Croft 1999; Shinmen et al. 2010). From this viewpoint, the fact that $P$. citri does not move in response to external stimuli strongly suggests that the benefits of avoiding predatory mites are larger than the costs of coincidental intraguild predation that are relatively rare event for the mite.

\section{Additional files}

Additional file 1: The moment of an unsuccessful attack (1).

Lying $P$. citri adult females never moved in response to the predatory mite E. sojaensis. Before long, the predator gave up and stopped approaching $P$. citri because of the interfering setae. 
Additional file 2: The moment of an unsuccessful attack (2). A female E. sojaensis that was attempting to approach the body surface of a lying $P$. citri female was repelled by an elastic seta (at the indicated time point of 16:25:34).

\section{Competing interest}

The authors declare that they have no conflict of interest.

\section{Authors' contribution}

SY and KS carried out experiments. SY drafted the manuscript. Both authors read and approved the final manuscript.

\section{Acknowledgements}

We thank M. Sudo and T. Sekido for valuable technical suggestions. This work was supported by the Japan Society for the Promotion of Science (Basic Research C; grant number 21580066 to SY). The present experiment complies with the current laws of Japan.

Received: 10 September 2013 Accepted: 21 November 2013 Published: 27 November 2013

\section{References}

Dawkins R, Krebs JR (1979) Arms races between and within species. Proc R Soc Lond B 205:489-511

Ehara S, Gotoh T (1992) Descriptions of two Panonychus spider mites from Japan, with a key to species of the genus in the world (Acari: Tetranychidae). Appl Entomol Zool 27:107-115

Fleschner CA, Badgley ME, Ricker DW, Hall JC (1956) Air drift of spider mites. J Econ Entomol 49:624-627

Fukaya M, Uesugi R, Ohashi H, Sakai Y, Sudo M, Kasai A, Kishimoto H, Osakabe M (2013) Tolerance to solar ultraviolet-B radiation in the citrus red mite, an upper surface user of host plant leaves. Photochem Photobiol 89:424-431

Inoue K, Osakabe M, Ashihara W (1987) Identification of pesticide resistant Phytoseiid mitepopulations in citrus orchards, and on grapevines in glasshouses and vinyl-houses (Acarina: Phytoseiidae). Jap J Appl Entomol Zool 31:398-403

Jones VP, Parrela MP (1984) Intratree regression sampling plans for the citrus red mite (Acari: Tetranychidae) on lemons in southern California. J Econ Entomol 77:810-813

Katayama H, Masui S, Tsuchiya M, Takara A, Doi M, Kaneko S, Saito T (2006) Density suppression of the citrus red mite Panonychus citri (Acari: Tetranychidae) due to the occurrence of Neoseiulus californicus (McGregor) (Acari: Phytoseiidae) on Satsuma mandarin. Appl Entomol Zool 41:679-684

McMurtry JA, Croft BA (1997) Life-styles of phytoseiid mites and their roles in biological control. Annu Rev Entomol 42:291-321

McMurtry JA, Huffaker CB, van de Vrie M (1970) Ecology of tetranychid mites and their natural enemies: A review. I. Tetranychid enemies: their biological characters and the impact of spray particles. Hilgardia 40:331-390

Mori K, Saito Y, Sakagami T (1999) Effects of nest web and female attendance on survival of young in the subsocial spider mite Schizotetranychus longus (Acari: Tetranychidae). Exp Appl Acarol 23:411-418

Nedelcu AM, Driscoll WW, Durand PM, Herron MD, Rashidi A (2011) On the paradigm of altruistic suicide in the unicellular world. Evolution 65:3-20

Nguyen TV, Shih C-IT (2012) Life-table parameters of Neoseiulus Womersleyi (Schicha) and Euseius Ovalis (Evans) (Acari: Phytoseiidae) feeding on six food sources. Int J Acarol 38:197-205

Oku K, Magalhaes S, Dicke M (2009) The presence of webbing affects the oviposition rate of two-spotted spider mites, Tetranychus urticae (Acari: Tetranychidae). Exp Appl Acarol 49:167-172

Osakabe M, Inoue K, Ashihara W (1986) Feeding, reproduction and development of Amblyseius sojaensis Ehara (Acarina: Phytoseiidae) on two species of spider mites and on tea pollen. Appl Entomol Zool 21:322-327

Osakabe M, Isobe H, Kasai A, Masuda R, Kubota S, Umeda M (2008) Aerodynamic advantages of upside down take-off for aerial dispersal in Tetranychus spider mites. Exp Appl Acarol 44:165-183

Pratt PD, Croft BA (1999) Expanded distribution of the bamboo spider mite, Schizotetranychus longus (Acari: Tetranychidae), and predation by Neoseiulus fallacies (Acari: Phytoseiidae). Acarologia 40:191-197
Sabelis MW, Bakker FM (1992) How predatory mites cope with the web of their tetranychid prey: a functional view on dorsal chaetotaxy in the Phytoseiidae. Exp Appl Acarol 16:203-225

Saito Y (1983) The concept of "life types" in Tetranychidae. An attempt to classify the spinning behaviour of Tetranichidae. Acarologia 24:377-391

Saito Y (1986a) Biparental defence in a spider mite (Acari: Tetranychidae) infesting Sasa bamboo. Behav Ecol Sociobiol 18:377-386

Saito Y (1986b) Prey kills predator: counter-attack success of a spider mite against its specific phytoseiid predator. Exp Appl Acarol 2:47-62

Shimoda T, Kishimoto H, Takabayashi J, Amano H, Dicke M (2009) Comparison of thread-cutting behavior in three specialist predatory mites to cope with complex webs of Tetranychus spider mites. Exp Appl Acarol 47:111-120

Shinmen T, Yano S, Osakabe M (2010) The predatory mite Neoseiulus womersleyi (Acari: Phytoseiidae) follows extracts of trails left by the two-spotted spider mite Tetranychus urticae (Acari: Tetranychidae). Exp Appl Acarol 52:111-118

Shirotsuka K, Yano S (2012) Coincidental intraguild predation by caterpillars on spider mites. Exp Appl Acarol 56:355-364

Smitley DR, Kennedy GG (1985) Photo-oriented aerial-dispersal behavior of Tetranychus urticae (Acari: Tetranychidae) enhances escape from the leaf surface. Ann Entomol Soc Am 78:609-614

Sudo M, Osakabe M (2011) Do plant mites commonly prefer the underside of leaves? Exp Appl Acarol 55:25-38

Vet LEM, Dicke M (1992) Ecology of infochemical use by natural enemies in a tritrophic context. Annu Rev Entomol 37:141-172

Wanibuchi K, Saito Y (1983) The process of population increase and patterns of resource utilization of two spider mites, Oligonychus ununquis (Jacobi) and Panonychus citri (McGregor), under experimental conditions (Acari: Tetranychidae). Res Popul Ecol 25:116-129

Yano S (2012) Cooperative web sharing against predators promotes group living in spider mites. Behav Ecol Sociobiol 66:845-853

doi:10.1186/2193-1801-2-637

Cite this article as: Yano and Shirotsuka: Lying down with protective setae as an alternative antipredator defence in a non-webbing spider mite. SpringerPlus 2013 2:637.

\section{Submit your manuscript to a SpringerOpen ${ }^{\circ}$ journal and benefit from:}

- Convenient online submission

- Rigorous peer review

- Immediate publication on acceptance

- Open access: articles freely available online

- High visibility within the field

- Retaining the copyright to your article

Submit your next manuscript at $>$ springeropen.com 